\title{
Introduction to the Special Issue on DHS in Africa
}

\author{
Antony Chikutsa \\ Department of Development Studies, Zimbabwe Open University \\ P.O. Box MP1119 Mount Pleasant Harare Zimbabwe \\ Email: chikutsaa@zou.ac.zw
}

The DHS program has conducted nationally-representative surveys worldwide, including Africa, since the mid-1980s. The data are open access and provide a rich resource for policymakers and scholars alike; however there has never been a special issue of a journal focusing on analysis of DHS data. The idea for a special issue on the theme of DHS in Africa emerged during the 2013 DHS Fellows program. It was determined that the African Population Studies Journal, as the only peer-reviewed bilingual journal of population studies in Africa, would be the most appropriate host for a special issue. On behalf of the team from the Zimbabwe Open University, I approached the Editor-in-Chief of the African Population Studies Journal, Prof. Clifford Odimegwu, about hosting this special issue.

An open call for submissions was issued in May 2013 which encouraged former DHS Fellows and capacity building workshop participants as well as others doing research using DHS data in Africa to submit papers. Papers were submitted by 31 October 2013. The initial selection process was done by the team at the Zimbabwe Open University and it involved selecting papers that focused on DHS in Africa. Papers that primarily relied on data obtained from other sources were not considered for this special issue. The contribution of Dr. Alfred C. Ncube and Mr. Shephard Mutsau, my fellow team members from the Zimbabwe Open University, is acknowledged during this process. After the initial selection, all papers were subjected to the standard review procedures of the African Population Studies Journal, using double-blind peer review mechanism. This review process was coordinated by the Editorin-Chief and the Editorial Board.

There were 78 submissions. After vigorous peer review processes only 26 manuscripts were recommended and approved by the Editorial Board of the Journal. The 26 manuscripts constitute this Special Issue. Many contributions are from authors based in Africa, including few from former DHS Fellows and capacity-building workshop participants. This special issue on DHS in Africa has some very interesting comparative studies. A paper by Patrizia Farina and Livia Elisa Ortensi examines the process of mother to daughter continuation of Female Genital Cutting in Egypt, Burkina Faso and Senegal. The study used the most recent DHS waves that include detailed information about the FGM experience of each daughter from Egypt (2008), Burkina Faso (20I0), and Senegal (2010-II). Also, a study by Rachel Sullivan Robinson, Ann Meier, Jenny
Trinitapoli and Joseph Svev looks at integrating Demographic and Health Surveys, IPUMS-I, and TerraPopulus to explore mortality and health outcomes at the District level in Ghana, Malawi and Tanzania. Another comparative by Katherine Harris, Victoria Hosegood and Andrew Channon examines gender disparities in HIV prevalence. In particular, the study focuses on a national level analysis of the association between gender inequality and the feminization of HIV/AIDS in sub-Saharan Africa.

This special issue has only one paper written in French. The paper by Abdoulaye Maïga and Banza Baya entitled La coexistence des générations en milieu urbain au Burkina Faso: Entre logique de sélection et obligation de parente examines the coexistence of generations in urban Burkina Faso.

On behalf of the 2013 DHS Fellows program and the Zimbabwe Open University team, I would like to thank Professor Clifford Odimegwu, the Editorin-Chief of the African Population Studies Journal and the entire Editorial board of APS for hosting this special issue on DHS in Africa. I would also like to thank the Vice Chancellor of the Zimbabwe Open University, Professor Primrose Kurasha and the Acting Dean of the Faculty of Applied Social Sciences, Dr Thomas Kaputa for their support. We are very grateful for the financial support we received for this project. We equally acknowledge the role of our peer-reviewers who contributed in improving the quality of the papers, without them editorial decisions would have been difficult. Financial support for the publication costs of this special issue was provided by the United States Agency for International Development (USAID) through the MEASURE DHS project (\#GPO-C-0008-00008-00). Staff from the MEASURE DHS 
project encouraged participants of DHS capacitybuilding workshops to submit papers, but was not involved in reviewing, selecting or editing papers, nor in ensuring that the analysis of DHS data was carried out correctly. The views expressed are those of the authors and do not necessarily reflect the views of USAID, MEASURE DHS, or the United States Government. 